\title{
The forces acting on the teeth of catching machine
}

\author{
Rustam Ergashev*1, Fakhriddin Bekchanov ${ }^{1}$, Jaloliddin Rashidov ${ }^{1[0000-0001-5593-9232]}$, and \\ Boybek Kholbutaev ${ }^{2}$ \\ ${ }^{1}$ Tashkent Institute of Irrigation and Agricultural Mechanization Engineers, 100000 Tashkent, Uzbekistan \\ ${ }^{2}$ Jizzakh Polytechnic Institute, 130100 Jizzakh, Uzbekistan
}

\begin{abstract}
Republic of Uzbekistan, pumping stations are used in very difficult conditions. The presence of various particles and effluents in the water has a negative effect on the operating modes of the pumping equipment. Special grilles are installed to prevent the catching devices from entering the advance chamber of the pump station. The shape and length of the device covers are of great importance so that they are caught in front of the grilles and completely cover the accumulated debris. In the article, the laws of mechanics were used to determine the shape and size of the working device of the device for cleaning the effluent flowing into the pump station as water and accumulated in front of the grids. In doing so, the condition of ensuring complete removal of the leaks covered by the device was taken into account. It was argued that the angle $\gamma$ between the working surfaces and velocities of the covers should be less than $90-\varphi$ over its entire working surface in order to fully cover the device shafts. It was found that when the working surface of the device is flat, the time of interaction with the catching device pieces is minimal. Studies and literature have shown that the angle of friction on the working surfaces of the device covers should be $\varphi=20^{\circ}$, the angle between the working surface of the device cover and the rotational speed $\gamma=70^{\circ}$.
\end{abstract}

Keywords. Pump station, fore chamber, cage, mouth, device, suction pipe, cavitation.

\section{Introduction}

Extremely turbid water in the country's sources, parts of pumping units that carry water, including bodies, substances, effluents, including impellers, fail mainly due to mechanical effects and cavitation erosion $[1,2]$. It is necessary to ensure the geodetic suction height of the water level in the avant-garde to prevent cavitation erosion that occurs on the working blades of the pump unit. In cases where the water is clean and flows at the same flow rate without obstruction, the suction height in the vane chamber can be ensured [3-5]. Russian Scientists from the Siberian State Technological University, V.P. Korpachev and A.I. Perezhilin, studied the causes of water pollution in hydropower plants and recommended that reservoirs should be kept clean, mainly due to leakage of water from the shores [6].

In 2016-2020, research work showed that on the Amu-Bukhara canal, the Karshi main canal,

\footnotetext{
*Corresponding author: erustamrah@mail.ru
} 
the drop in water level in the avalanche occurred as a result of changes in water consumption in the Amudarya, the muddy filling of canals and the formation of artificial barriers $[7,8]$.

The change in the period and volume of discharge of effluents from the Amudarya to the pumping stations depends on the following [9]:

- at the beginning of the irrigation season to the time of the first supply of water to the pump station;

- the amount of tree stems, roots, which are washed away due to the increase in water consumption in the river, the water changes its course and flows with it;

- the type of waste generated by industrial, manufacturing and domestic organizations located along rivers and canals;

- due to the location of pastures and meadows along the coast, the animals can accidentally fall, drown and flow to the pumping stations.

Fences have been installed in the Amu-Bukhara-1 and Amu-Bukhara-2 car canals to trap water leaks and prevent it from entering the pumping station (Fig. 1).

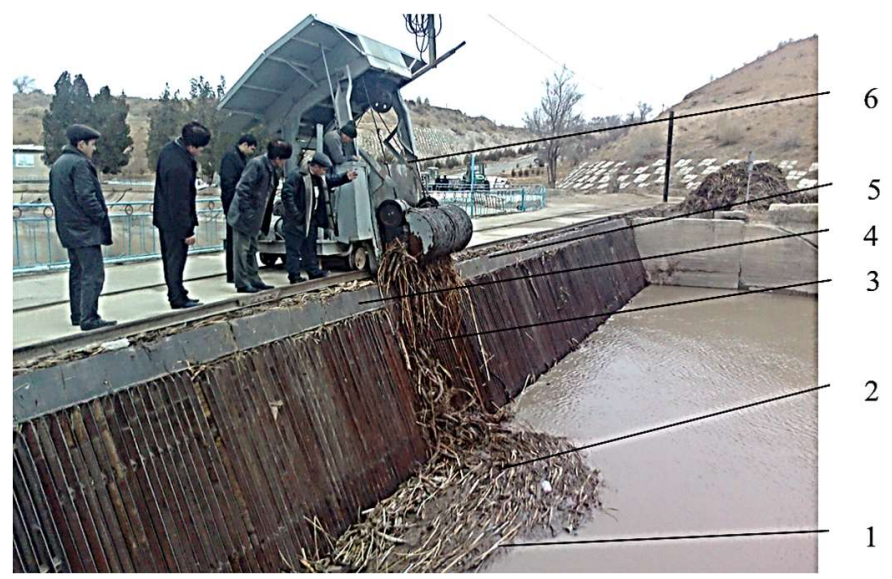

Fig. 1. The process of removing debris collected in front of the grate at the pump station Amu-Bukhara-1: 1 - mouth; 2 - grid holding traps; 3 - streams falling back into channel; 4 - car moving rails; 5 - dryer cover; 6 - the machine that moves the cleaning device.

The different nebulae of the runoff, the rapid change in size throughout the year, and the erratic flow in different directions cause the water to accumulate in front of the installed fences and block the waterway (Fig. 2).

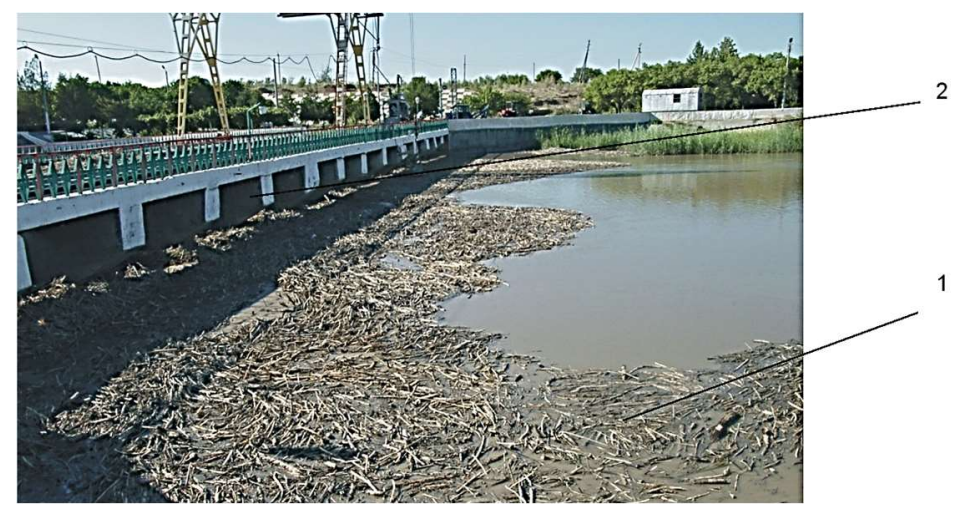

Fig. 2. Collection of effluents in front of the grate at the Amu-Bukhara-2 pumping station: 1 - mineral and organic particles; 2 - water access paths to the forechamber. 
At the Amu-Bukhara-1 and Amu-Bukhara-2 pumping stations, one of the main reasons for the drop in the water level in the vane chamber was the failure of the device to fully meet the requirements $[10,11]$. As a result of untimely cleaning of the gutters in front of the fences installed in front of the van, the water became stagnant, which led to a drop in the water level in the van.

A drop in the water level in the vane chamber creates water clusters in front of the suction pipes, which leads to the absorption of air into the pump and a decrease in performance $[12,13]$.

Therefore, the improvement of the technology of cleaning and removal of debris is one of the important issues. The aim of the study was to substantiate the parameters of the device workstation, which provides for the cleaning and removal of debris accumulated in front of the grilles (Fig. 3). The following issues have been resolved to achieve this goal:

- to determine the forces acting on the device covers to ensure that the debris accumulated in front of the grille is completely covered and removed;

- to determine the shape of the cover to ensure complete removal and removal of debris that has accumulated in front of the grilles [14].

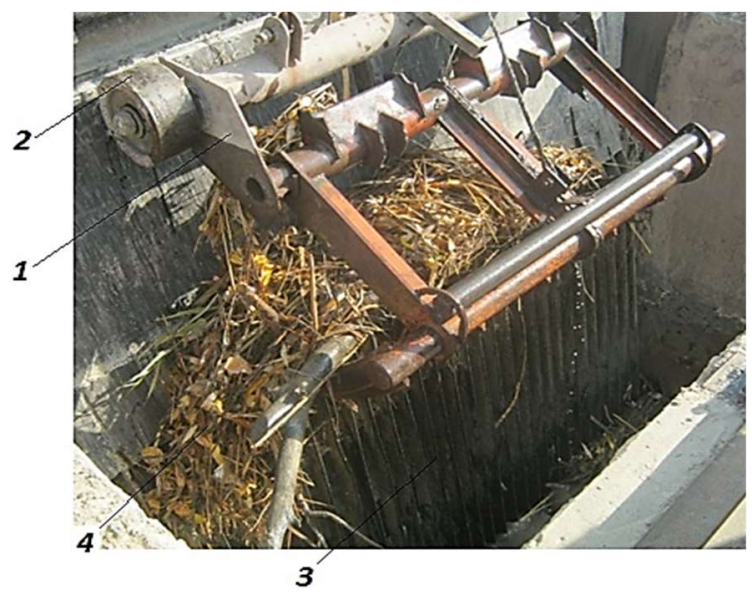

Fig. 3. The process of covering the mouths: 1 - device base; 2 - device base wheels; 3 - grid holding traps; $4-$ a set of mouthpieces with different contents.

\section{Method}

The forces acting on it were determined using the laws of mechanics to determine the shape and size of the work piece of the device that cleans the debris that flows into the pump station avanker along with the water and accumulates in front of the grilles. In doing so, the condition of ensuring complete removal of the leaks covered by the device was taken into account.

\section{Results and discussion}

The shape and length of the device covers are of great importance so that they are caught in front of the grilles and completely cover the accumulated debris. To ensure that the lugs that have accumulated in front of the grilles are completely covered and cleaned, we will first consider the forces acting on the lugs by the device lining. During the process of covering the device shafts, its $M$ part is affected by normal $N$ and frictional forces $F$ by the device cover (Fig. 4). We divide the normal force $N$ acting on the $M$ part of the catching device into two influences: the device velocity $V_{M}$ in the process of covering the catching devices, i.e., $N_{v}$ directed along its rotation speed relative to point 0 , and $N_{\tau}$ directed along the working surface of the catching device [15-19]:

$$
N_{\tau}=N_{c t g} \gamma
$$


and

$$
N_{v}=\frac{N}{\sin \gamma},
$$

where $\gamma$ is the angle between the working surface of the device cover and the rotational speed $V_{M}$. For the catching devices to be completely covered by the device cover, the force $N_{\tau}$ must be greater than the friction force $\mathrm{F}$, i.e.

$$
N_{\tau}>F \text {. }
$$

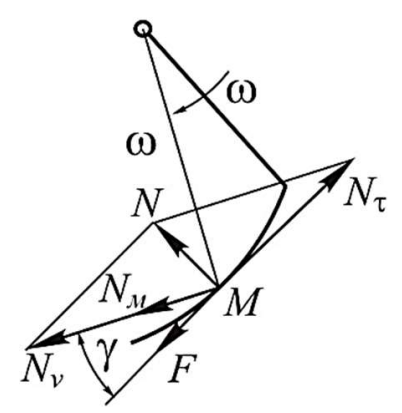

Fig. 4. A diagram of the forces acting on the parts of the mouthpiece by the cover of the device cover.

This is because only when this condition is met is it ensured that the catching devices are pushed upwards along the covers of the device cover, which are completely covered by the device. (3) Substituting the value of $N_{t}$ in the expression (1) and taking into account that $F=f N=N \operatorname{tg} \varphi$ (where $f$, ph is the coefficient of friction and angle of friction on the working surfaces of the device covers, respectively, we obtain the following result:

$$
N_{\operatorname{ctg} \gamma}>N_{\operatorname{tg} \varphi} \text {. }
$$

We solve this expression with respect to $\tau$ :

$$
\gamma>90-\varphi \text {. }
$$

Hence, in order to fully cover the device surfaces, the angle $\gamma$ between the working surfaces and velocities of the device covers must be less than $90-\varphi$ over its entire working surface, i.e., condition (5) must be met. We now move on to justify the shape of the working surfaces of the device cover covers. In solving this problem, we proceed from the condition that the time of interaction between the working surface of the cover and the parts of the mouth is minimal [20-29]. This is due to the fact that, firstly, the sheets are easily moved along the working surface, and secondly, the technological process is carried out with minimal energy consumption. Let us consider the motion of the axial segments in the ZOX coordinate system (where the $\mathrm{OX}$ axis is horizontal and the $\mathrm{OZ}$ axis is perpendicular) under the influence of the coverage, whose working surface has an arbitrary curved shape (Fig. 5).

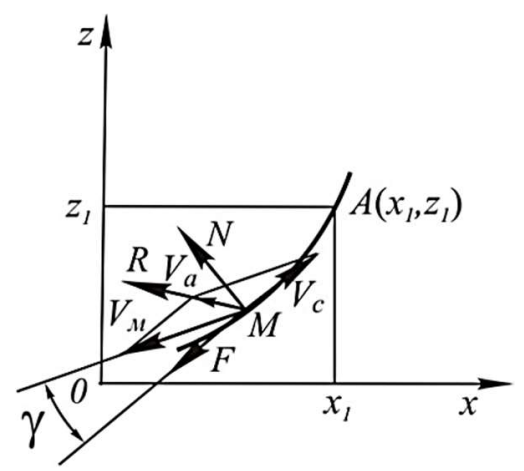

Fig. 5. The shape of the working surfaces of the device covers justification scheme. 
In this coordinate system, the axial fragments rotate under the influence of the normal $N$ and friction forces acting on them, $V_{M}$, and the relative sliding motion $V_{c}$ with velocity along the working surfaces of the overlaps [1-2].

It is directed along the force $R$, which is an equal effect of the forces $F$.

In this case, the absolute velocity of the axial fragments $V_{a}$ is equal to the geometric sum of the velocities $V_{m}$ and the relative $V_{c}$ velocities, i.e. $V_{a}=\sqrt{V_{M}^{2}+V_{c}^{2}-2 V_{\mu} V_{c} \cos \gamma}$ and $N$ and it is directed along the force $R$, which is an equal effect of the forces $F$. Using the scheme shown in Fig. 5, we express the velocity $V_{c}$ in terms of velocity $V_{m}$ and determine the slip time $t$ from point $0(0.0)$ to the point $A\left(x_{1}, z_{1}\right)$ of the working surface of the device cover of the slice $M$ :

$$
\begin{gathered}
V_{c}=V_{M} \frac{\cos (\gamma+\varphi)}{\cos \varphi}=V_{M}(\cos \gamma-\sin \gamma \operatorname{tg} \varphi) ; \\
t=\int_{0}^{X_{1}} \frac{\sqrt{d x^{2}+d z^{2}}}{V_{c}}=\int_{0}^{X_{1}} \frac{\sqrt{1+\left(z^{\prime}\right)^{2}}}{V_{M}(\cos \gamma-\sin \gamma \operatorname{tg} \varphi)} d x .
\end{gathered}
$$

Assuming that the device covers are oriented $\mathrm{V}_{\mathrm{m}}$ horizontally in the process of covering the gaps, we express the sing and cosg in expression (7) by $d x$ and $d z$ :

$$
\sin \gamma=\frac{d z}{\sqrt{d x^{2}+d z^{2}}}=\frac{z^{\prime}}{\sqrt{1+\left(z^{\prime}\right)^{2}}}
$$

and

$$
\cos \gamma=\frac{d z}{\sqrt{d x^{2}+d z^{2}}}=\frac{1}{\sqrt{1+\left(z^{\prime}\right)^{2}}} .
$$

Given these expressions, expression (7) has the following appearance:

$$
t=\frac{1}{V_{M}} \int_{0}^{x_{1}} \frac{1+\left(z^{\prime}\right)^{2}}{1-z^{\prime} \operatorname{tg} \varphi} d x
$$

We examine this expression to the extremum under the following condition:

$$
\frac{d}{d x}\left(F_{z^{\prime}}+F_{z}\right)=0
$$

where $F_{z}$ ' and $F_{z}$ are specific derivatives of the function $F$ on $z$ ' and $z$, respectively;

$F$ - (11) function under the integral of the expression.

(11) function under the integral according to the expression:

$$
F \frac{1+\left(z^{\prime}\right)^{2}}{1-z^{\prime} \operatorname{tg} \varphi} \text {. }
$$

It can be seen from this expression that the function $F$ does not depend on $z$. Therefore, expression (11) has the following appearance:

$$
\frac{d}{d x} F_{z^{\prime}}=0
$$

To fulfill this condition should be:

$$
F_{z^{\prime}}=\frac{\partial F}{\partial z^{\prime}}=\text { const } ; \frac{d}{d x} F_{z^{\prime}}=0
$$

Because only then the condition is fulfilled. Taking a special derivative of $z$ ' from expression (12), we obtain the following.

$$
\frac{\partial F}{\partial z^{\prime}}=\frac{2 z^{\prime}\left(1-z^{\prime} \operatorname{tg} \varphi\right)+\left[1+\left(z^{\prime}\right)^{2}\right] \operatorname{tg} \varphi}{\left(2-z^{\prime} \operatorname{tg} \varphi\right)^{2}} .
$$


According to the expression (14), this expression must have a constant size, as such where $C$ is a constant quantity:

$$
\frac{2 z^{\prime}\left(1-z^{\prime} \operatorname{tg} \varphi\right)+\left[1+\left(z^{\prime}\right)^{2}\right] \operatorname{tg} \varphi}{\left(2-z^{\prime} \operatorname{tg} \varphi\right)^{2}}=C,
$$

decomposing the expression (16) with respect to $z$, it is generally written as follows:

$$
z^{\prime}=f(\varphi)=\text { const. }
$$

This expression indicates that in order for $t$ to have an extreme value, $z^{\prime}=$ const the device cover must have a flat working surface, as only that is ensured.

When the working surface of the device covers is flat (7), the expression will have the following appearance:

$$
t=\frac{\ell_{T}}{V_{M}(\cos \gamma-\sin \gamma \operatorname{tg} \varphi)}
$$

where $l_{T}$ is the length of the working surfaces of the device covers.

Therefore, based on the above, it can be said that in order to ensure the quality of the technological process at the required level with low energy consumption, the working surface of the device cover should be in the form of a flat surface installed at an angle of less than $90-\varphi$ to the horizon.

In our study and in the literature, it was found that when the $\varphi=20^{\circ}$ is, the expression (5) should be $\gamma=70^{\circ}$.

\section{Conclusion}

The presence of various particles and effluents in the water adversely affects the operating modes of the pumping equipment. Special grids will be installed in the channel to prevent the contents of the water from entering the advance chamber of the pump station. The shape and length of the device covers are of great importance so that they are caught in front of the grilles and completely cover the accumulated debris. The correct selection of the shape and size of the workpiece ensures complete removal of the catching devices covered by the device. When the angle $g$ between the working surfaces and velocities of the device covers is less than $90-\varphi$ over its entire working surface, it is theoretically justified that the gaps accumulated in front of the grids are completely covered. One of the main conditions is that full coverage and cleaning is ensured when the interaction time of the catching device set with the device cover, where the working surface is flat, is minimal. Studies and literature have shown that the angle of friction between the working surfaces of the device covers should be $\varphi=20^{\circ}$, the angle between the working surface of the device cover and the rotational speed $\gamma=70^{\circ}$.

\section{References}

1. M. Mamajonov, D.R. Bazarov, B.R. Uralov, G.U. Djumabaeva, N. Rahmatov. The impact of hydro-wear parts of pumps for operational efficiency of the pumping station, Journal of Physics: Conference Series 1425, 012123 (2019). DOI: 10.1088/1742-6596/1425/1/ 012123 .

2. D. Bazarov, N. Vatin, O. Bakhtiyor, V. Oybek. Hydrodynamic effects of the flow on the slab of the stand in the presence of cavitation, IOP Conference Series: Materials Science and Engineering 1030, 012110 (2021). DOI: 10.1088/1757-899X/1030/1/012116.

3. Dilshod Bazarov, Irina Markova, B.N., O.V. Hydraulic aspects of the layout of head structures during water intake from lowland rivers, IOP Conference Science, Materials 1015, 012041 (2021). DOI: 10.1088/1757-899X/1015/1/012041. 
4. O. Glovatsky, R. Ergashev, A. Saparov, M. Berdiev, B. Shodiev. Cavitation-abrasive wear working collectors of pumps, IOP Conference Series: Materials Science and Engineering 869 (4), 042006 (2020).

5. J. Rashidov, B. Kholbutaev. Water distribution on machine canals trace cascade of pumping stations, IOP Conf. Ser. Mater. Sci. Eng. 883, (2020).

6. O. Glovatsky, R. Ergashev, A. Saparov, M. Berdiev, B. Shodiev. Cavitation-abrasive wear working collectors of pumps, IOP Conference Series: Materials Science and Engineering, (2020).

7. V.P. Korpachev, A.I. Perezhilin. Zagryazneniye $i$ zasoreniye vodokhranilishch GES drevesno-kustarnikovoy rastitel'nost'yu, organicheskimi veshchestvami i vliyaniye ikh na kachestvo vody: monografiya Rossiyskoy Akademii Yestestvoznaniya, 148 (2010).

8. O.Ya. Glovatskii. Operating experience and reliability assessment of elements of pumping stations, Hydrotechnical Construction 23 (9), 532-537 (1989).

9. S. Song, G. Sang, L. Zhang, W. Wang. Study on the Hydraulic Characteristics of Cascade Pumping Station on the East Route of South-to-North Water Diversion Project, IOP Conference Series: Earth and Environmental Science 170, (2018).

10. R. Ergashev, F. Artikbekova, G. Jumabayeva, F. Uljayev. Problems of water lifting machine systems control in the republic of Uzbekistan with new innovation technology, E3S Web of Conferences, (2019).

11. S.I. Basok, Ji.A. Kamyshentsev, I.V. Kononov, Yu.V. Sokolov, V.M. Aksinin. Ustroystvo dlya ochistki sorouderzhivayushchey reshetki //A.C. № 1172986. Byull. izobr. № 30, $19853 \mathrm{~s}$.

12. A. Krutov, R. Choriev, B. Norkulov, D. Mavlyanova, A. Shomurodov. Mathematical modelling of bottom deformations in the kinematic wave approximation, IOP Conference Series: Materials Science and Engineering 1030, 012147 (2021). DOI: 10.1088/1757899x/1030/1/012147.

13. A. Krutov, B. Norkulov, F. Uljaev, F. Jamalov. Results of a numerical study of currents in the vicinity of a damless water intake, IOP Conference Series: Materials Science and Engineering 1030, 012121 (2021). DOI: 10.1088/1757-899x/1030/1/012121.

14. B. Matyakubov, I. Begmatov, I. Raimova, G. Teplova. Factors for the efficient use of water distribution facilities, IOP Conference Series: Materials Science and Engineering 883, 012025 (2020). DOI: 10.1088/1757-899x/883/1/012025.

15. B. Obidov, O. Vokhidov, D. Tadjieva, D. Saidkhodjaeva, U. Kurbanova, A. Isakov. Hydrodynamic effects on the flow elements of the downstream devices in the presence of cavitation, IOP Conference Series: Materials Science and Engineering 1030, 012114 (2021). DOI: 10.1088/1757-899x/1030/1/012114.

16. A. Baghlani. Optimal control of pumping stations in open channels by metaheuristic firefly algorithm Civil and Environmental Engineering Department, Shiraz University of Technology, Shiraz, Iran international journal of optimization in civil engineering, Int. J. Optim. Civil Eng. 2 (3), 369-382 (2012).

17. B. Dilshod, I. Markova, S. Sultanov, F. Kattakulov. Dynamics of the hydraulic and alluvial regime of the lower reaches of the Amudarya after the commissioning of the Takhiatash and Tuyamuyun hydrosystems, IOP Conference Series: Materials Science and Engineering 1030, 012110 (2021). DOI: 10.1088/1757-899X/1030/1/012110.

18. S. Eshev, S. Latipov, A. Qurbonov, J. Sagdiyev, M. Berdiev, N. Mamatov. Non-eroding speed of water flow of channels running in cohesive soils, IOP Conference Series: Materials Science and Engineering 1030, 012131 (2021). DOI: 10.1088/1757899x/1030/1/012131.

19. N. Ikramov, T. Majidov, E. Kan, D. Akhunov. The height of the pumping unit suction pipe inlet relative to the riverbed bottom, IOP Conference Series: Materials Science and Engineering 1030, 012125 (2021). DOI: 10.1088/1757-899x/1030/1/012125. 
20. E. Kan, A. Muratov, M. Yusupov, N. Ikramov. Calculation of water hammer on the pressure pipeline of modernized irrigation pumping station, IOP Conference Series: Materials Science and Engineering 1030, 012127 (2021). DOI: 10.1088/1757$899 x / 1030 / 1 / 012127$.

21.S. Khidirov, G. Jumaboeva, Z. Ishankulov. Hydraulic mode of operation of the Takhiatash hydroelectric complex, (2021). DOI: 10.1088/1757-899X/1030/1/012120.

22. A.M. Bagirov, A.F. Barton, H. Mala-Jetmarova, et al. An Algorithm for Minimization of Pumping Costs in Water Distribution Systems using a Novel Approach to Pump Scheduling, Mathematical and Computer Modelling 57 (3-4), 873-886 (2013).

23. Q. Pan, W. Shi, D. Zhang, B.P.M. van Esch, R. Zhao. Fish-friendly design of an axial flow pump impeller based on a blade strike model, Proc. Inst. Mech. Eng. Part A J. Power Energy 234, 173-186 (2020).

24. O. Glovatsky, R. Ergashev, A. Saparov, M. Berdiev, B. Shodiev. Cavitation-abrasive wear working collectors of pumps, IOP Conference Series: Materials Science and Engineering 869 (4), 042006 (2020).

25. B. Urishev, F. Artikbekova, D. Kuvvatov, F. Nosirov, U. Kuvatov. Trajectory of sediment deposition at the bottom of water intake structures of pumping stations, IOP Conference Series: Materials Science and Engineering 1030, 012137 (2021). DOI: 10.1088/1757899x/1030/1/012137.

26. F. Shaazizov. Studies of turbulent flow characteristics of dividing open water streams, IOP Conference Series: Materials Science and Engineering 1030, 012141 (2021). DOI: 10.1088/1757-899x/1030/1/012141.

27. Z. Mamatkulov, J. Rashidov, G. Eshchanova, M. Berdiev, Z. Abdurakhmonov. Visualization and analysing the state of hydrotechnical construction via geospatial methods (on the example of Kharshi pumping stations cascade), IOP Conf. Ser. Earth Environ. Sci. 614, (2020).

28. A.R. Khafizov, F.F. Kamaletdinov, A.B. Yakushkina, I.V. Nedoseko. Construction regulatory systems to protect the banks of the Ufa river in the area of Ufa water intake, Izvestiya KGASU 1 (51), 118-127 (2020).

29. R.Kh. Mukhametrakhimov, A.A. Panchenko. Features of the quality control system for the construction of outdoor water supply and sewerage networks, Izvestiya KGASU 4 (42), 360-367 (2017). 